\title{
The Exploration of Internet of Things Applied at Universities
}

\author{
Chen Lin \\ Educational Science College of Chongqing Normal University \\ Chongqing, China \\ E-mail: chenlin_800123@163.com
}

\begin{abstract}
Internet of things, as an emerging technology, has been applied and developed in many fields. Based on the current researches and application of Internet of Things at domestic colleges and universities, this paper is going to explore the applicability of Internet of Things at universities. In this paper the author will carry out the research and survey and list some examples to figure out how to apply the Internet of Things in domestic universities. Its application at domestic universities has been being actively explored. Nearly one hundred establishments have carried out the research and implemented the application of sensors. The research and production bases at Shanghai Institute of Micro-system And Information Technology of Chinese Academy of Science and Peking University have been established. Beijing University of Posts and Telecommunications and Nanjing University of Posts and Telecommunications have entered the actual construction phase for Internet of Things. Through the present research, the conclusion is the introduction of Internet of Things to universities, which will bring changes to the quality and efficiency of work especially in terms of materials management. However, due to its higher construction cost and other reasons, researchers still need more sources and investments to achieve it.
\end{abstract}

Keywords-Internet of Things; Universities; Applicability; Exploration; RFID

\section{DEFINITION OF INTERNET OF THINGS}

Internet of things (IOT) first appeared in Bill Gates's book The Road Ahead[1], which was published in 1995. The book brought up the prototype of the Internet of Things. After 20 years, the definition of Internet of things is still evolving. A precise and authorized definition has not been formed. Currently the widely accepted definition is that Internet of Things is an information network using connecting technology of things-to-things, peopleto=things and people-to-people to achieve information exchange through the agreed communication protocols among variety of information sensing equipment and systems (sensor networks, radio frequency identification system, infrared sensors, laser scanners, etc.), bar code and QR code and global positioning system in order to realize intelligent identification, location tracking, monitoring and management. The main features of Internet of Things, as the core of definition are each object that can be addressed, controlled and communicate. That is to say, through an interface connected to a variety of wireless access network, Internet of Things can be accessed to give things smart property to achieve communication and dialogue between mankind and objects, between objects and objects and make objects have comprehensive sensing ability, with reliable data transmission and intelligent processing capabilities to connect things and things of the information network[2].

\section{APPLICATION AND DEVELOPMENT OF IOT IN}

\section{COMMUNITIES}

Let's take a look at the applications of Internet of Things in other fields before talk about its application at universities. For example, the products of IOT such as sensors have been used in the anti-intrusion system of Shanghai Pudong International Airport, within which there are more than 30,000 sensor nodes [3], covering the ground, fences and low-altitude detection that can prevent personal climbing and crossing. IOC controls lighting system at the Garden Expo Park in Jinan, where the wire less lighting control system of IOT is adopted in all functional lighting. The combination of IOT with door access control systems or command centers, as well as RFID technology applied in food safety gives us references for the application of IOT at universities.

\section{APPLICATION OF IOT ON CAMPUS SECURITY}

With large-area campuses, large number of teachers and students and complex environment surrounding the campuses, universities can use IOT to do real-time monitoring on campus without time and space constraints, to achieve all-weather, all terrain smart security management. For example, connect the image acquisition points into network to do real-time remote monitoring, so the unified management and monitoring on campus security can be achieved. In some dangerous areas on campus, such as waters sides, attic, construction sites or dead corners, the RFID readers should be installed to identify students and automatically send voice alerts when they are present at these sites; multiple sensors should be installed in areas where visitors are not allowed to enter, such as teaching area and student dormitories. When visitors enter these areas, voice alarm will be activated automatically to notify the security personnel to deal with it timely; mount RFID tags on school motor vehicles so they can be identified when go through gates. The information on dwell time and accurate location can be integrated into information management platform and personal cellphones; in densely populated areas, such as classrooms, laboratories, dormitories, libraries and stadiums, sensors should be installed intensively to 
monitor parameters such as ambient temperature and smoke concentration. In case any abnormality occurs, the sprinkler system will start automatically, and the location information and other relevant parameters can be transmitted to the fire control center for real-time alarm fires, accurate positioning and timely control[4].

\section{APPLICATION OF IOT ON ENERGY CONSERVATION}

\section{AT UNIVERSITIES}

Classrooms are most common places in universities and where the IOT is used most frequently. With arranged sensors in classrooms, every corner of the classroom can be monitored on temperature and light etc., and automatic adjustment of the brightness of the lighting and airconditioning temperature based on the preset valve value can be achieved. Therefore, students are provided with a comfortable learning environment, and it can also save energy. In addition, the classroom and laboratory lighting, air conditioning, computers and other equipment can automatically control the power switch based on the number of people present. Power load of students' dormitories can also achieve real-time remote monitoring through IOT[5]. Dramatic changes in electricity load can be detected to prevent fire, electric shock and other personal injury accident, to achieve effective regulation of electricity and energy saving.

Campus energy conservation is also very important. Intelligent lighting is an application of IOT technology, so that each lamp can be remotely monitored and controlled. Outdoor lights and streetlights accept commands from the control center and send feedback to it. The illumination brightness can be adjusted based on light intensity and different periods. For example, install sensors on both sides of the road to monitor brightness and control the onand-off of lights. According to outdoor light intensity and time period to adjust the brightness, when the outdoor lighting is dim, lights will be turned on automatically; when the light is relatively strong, the lights will automatically be turned off. In case of the special period (such as late at night), you can control intelligent light switches or interval control the bright lights, in order to achieve the purpose of energy saving[6].

\section{APPLICATION OF IOT ON THE CONSTRUCTION OF \\ SMART LIBRARIES AT UNIVERSITIES}

Smart library construction: With the expansion of major colleges and universities, their collection of books is also growing, coupled with the presence of book shelving errors and other issues, the traditional search through book barcode will waste a lot of time. With convenient RFID tag attached to the book, a plurality of readers in the collection range, determine the orientation of the book by the reader coordinate information and transmitted to the location server, location server administrator login readers and book information inquiry with a client or a mobile phone, the book shelves, shelving books and books disorder finishing work to improve the search for missing books and inventory documentation efficiency. You can also use the self-help book machine devices with RFID tags pasted books to scan, identify and return process could help readers to self-service return books, renew operations, to avoid queuing, a high degree of RFID logistics management way, so as to effectively enhance the library management efficiency, simplify library management processes, reduce labor intensity of library management personnel, to provide readers with a more convenient and efficient book by book, for such services [7].

\section{APPLICATION OF IOT ON MATERIALS MANAGEMENT AT UNIVERSITIES}

The introduction of RFID-based networking to Materials Management, establish college materials management system of IOT. For example, a large number of colleges and universities teaching equipment and facilities are distributed randomly, difficult to manage, and have no special management and maintenance. By giving all kinds of RFID tags attached to the equipment or installation of sensors and assigning staff management, the unified management and scheduling can effectively prevent the loss and the low utilization rate of equipment and other issues. You can also solve the bottleneck of data dispersed collection and input to achieve real-time, dynamic and efficient fixed-assets management[8].

\section{PROBLEMSENCOUNTERED FOR THE INTRODUCTION} OF IOT INTO UNIVERSITIES

\section{A. Insufficient Maturity for the Current Technology of IOT}

As an emerging technology industry, IOT has been getting widespread attention in recent years. However, from its development process, the technology of IOT in China is still at the initial stage, and the future development of IOT will go through four stages. Before 2010, RFID is widely used in logistics, retail and pharmaceutical fields; from 2010 to 2015, things interconnected; 2015 to 2020[9], things enter the semiintelligent age; after 2020 it will be the All-intelligent age. The definition of IOT is not uniform and it can be said IOT at current stage is not mature.

\section{B. Insufficient Conditions for the Construction ofIOT at Universities}

Internet of Things is composed of various sensors, bar codes, two-dimensional code, RFID devices, cameras, GPS and other terminals; network layer by a variety of private networks, the Internet, wired and wireless network management systems and cloud computing platforms and other components. IOT is composed of hardware and software. Selection of electronic tags for the hardware, the main targets in the asset management system of universities requires an electronic tag and selection and installation of RFID reader, network construction, the server stores data services and a range of related equipment. There are various kinds of hardware, which brings a lot of trouble to select. There is application platform, construction and management staff for the software. IOT is the technology whose application is being explored, and lack of professionals cause inconvenience for the construction of IOT and later maintenance. Its cost is still high.

The introduction of IOT into universities will bring many changes. However, due to the immaturity of its 
technology, diverse ways of applications and construction conditions, the introduction also brings other unfavorable factors. Based on qualitative considerations, the large-scale investment on IOT at universities outweighs the benefits generated[10].

\section{CONCLUSIONS}

As an emerging technology, Internet of Things has a long-term prospect. It is beyond doubt that its introduction into universities will bring changes to the quality and efficiency of work especially in terms of materials management. However, the core technology is held by other countries, and it is not the best time to introduce IOT into universities due to its higher construction cost and other reasons. In the present opinion, with the maturity of networking technology and many other conditions, the university will be able to enjoy the convenience that Internet of Things brings.

\section{REFERENCES}

[1] Liu Huajun, Liu Chuanqing, "Internet of Things Technology," Beijing Electronic Industry Press, 2010.9:1-13.
[2] Wu Wei, Wu Wei, Luo Lianhel, "Internet of Things in online Communication Technology, 'Electronic Industry Press,2012.6:212.

[3] Wang Jing, "TQC management based on Internet of Things at Universities,"Collected Papers of 12th Academic Annual Meeting of Technology \& Material Seminar by Beijing Higher Education Society,2010.12.

[4] Ding Feng, Wang Qifeng, Liu Bing, "The Role of Universities in the Development of IOT Industry," College of Electronic and Information Engineering, 2013.8.

[5] Ding Qiong, "Research and Realization on University Assets Management System based on IOT," Gui Zhou College of Industrical Vocational Technology, 2013.5.

[6] Liang Zheng, "Research on Facility Management System at Universtiy Based on IOT," Shanghai Institution of Tourism, 2013.12.

[7] Lin Qiuping, "Research on Construction of Smart Logistic Laboratory at Universities based on IOT,"Xinjiang University of Finance and Economics, 2013.6.

[8] Hao Zhiqi, Yang Qiankun, "Int egrated Management on University Teaching based on IOT,'The School of Management, Hefei University of Technology, 2013.3.

[9] http://baike.baidu.com/link?url=M8pJDZd7_W3Lbwb_K6S4QiL3koBG26uCpX39uN4JeeSFM9oyM6T0 Pt4kPyJaz2Fq1 g1 QwlKBPJ4pd9I91VP9FnEKmGWZyyQamcDXZ $1 \mathrm{hWaW}$.

[10] http://iotcompetition.org/2014 